\title{
Allylic Oxidation of Alkenes Catalyzed by a Copper-Aluminum Mixed Oxide
}

\author{
Ana Leticia García-Cabeza, Rubén Marín-Barrios, F. Javier Moreno-Dorado, María J. Ortega, \\ Guillermo M. Massanet, and Francisco M. Guerra*
}

Departamento de Química Orgánica, Facultad de Ciencias, Universidad de Cádiz, 11510 Puerto Real, Cádiz, Spain

\section{Supporting Information}

ABSTRACT: A strategy for the allylic oxidation of cyclic alkenes with a copper-aluminum mixed oxide as catalyst is presented. The reaction involves the treatment of an alkene with a carboxylic acid employing tert-butyl hydroperoxide as the oxidant. In all cases, the corresponding allylic esters are obtained. When L-proline is employed, the allylic alcohol or ketone is obtained. The oxidation of cyclohexene and valencene has been optimized by design of experiments (DoE) statistical methodology.
$\mathrm{T}$ he allylic oxidation of an alkene is one of the simplest cases of $\mathrm{C}-\mathrm{H}$ bond activation. ${ }^{1}$ This transformation lacks a general methodology due to problems such as regio- and stereoselectivity, poor compatibility with other functional groups, overoxidation issues, etc. It is not common to find a total synthesis in which the key step lies in the allylic oxidation of an alkene, despite the fact that in many cases this sort of transformation could streamline a given route substantially. ${ }^{2}$

Classically, this transformation has been based mainly on the chemistry of $\mathrm{Se}, \mathrm{Cr}, \mathrm{Pd}$, and $\mathrm{Cu}$ species. ${ }^{3}$ Toxicity and cost are the main drawbacks of some of them, especially when the reagent has to be used in stoichiometric amounts. Additionally, remarkable efforts have been made by the White ${ }^{4}$ and Doyle ${ }^{5}$ groups based on $\mathrm{Pd}$ and $\mathrm{Rh}$, respectively, leading to commercial versions of their catalysts.

A lesser known approach employs a copper source and a stoichiometric amount of an oxidant, usually a perester. This reaction is known as the Kharasch-Sosnovsky reaction. ${ }^{6}$ First described in the later years of the 1950s, the reaction involves the oxidation of an alkene by tert-butyl peroxybenzoate in the presence of a copper or cobalt source, providing the corresponding benzoate ester (Figure 1a). An alternative is the employment of a carboxylic acid as the donor of acyloxy radicals, providing directly the corresponding allylic esters.

The Kharasch-Sosnovsky reaction is an interesting option that has not been fully exploited. ${ }^{8}$ Recently, we have reported the preparation of a new copper-aluminum mixed oxide $(\mathrm{Cu}-\mathrm{Al} \mathrm{Ox}$ henceforth) that catalyzes the allylic hydroxylation of enones. ${ }^{9}$ The electron-deficient double bond of the enone was oxidized with moderate to good yields employing $\mathrm{Cu}-\mathrm{Al} \mathrm{Ox}, t-\mathrm{BuOK}$, and molecular oxygen from the air as the oxidant (Figure 1b). In this work, we describe the allylic oxidation of cyclic alkenes catalyzed by $\mathrm{Cu}-\mathrm{Al} \mathrm{Ox}$ using tert-butyl hydroperoxide as the oxidant (Figure 1c).

$\mathrm{Cu}-\mathrm{Al} \mathrm{Ox}$ is prepared from $\mathrm{CuCl}_{2}$ and $\mathrm{AlCl}_{3} \cdot 6 \mathrm{H}_{2} \mathrm{O}$ by coprecipitation with $\mathrm{Na}_{2} \mathrm{CO}_{3}$ and $\mathrm{NaOH}$ in water. After heating at $70{ }^{\circ} \mathrm{C}$ for $22 \mathrm{~h}$, removal of water, and drying first in an oven $(105$
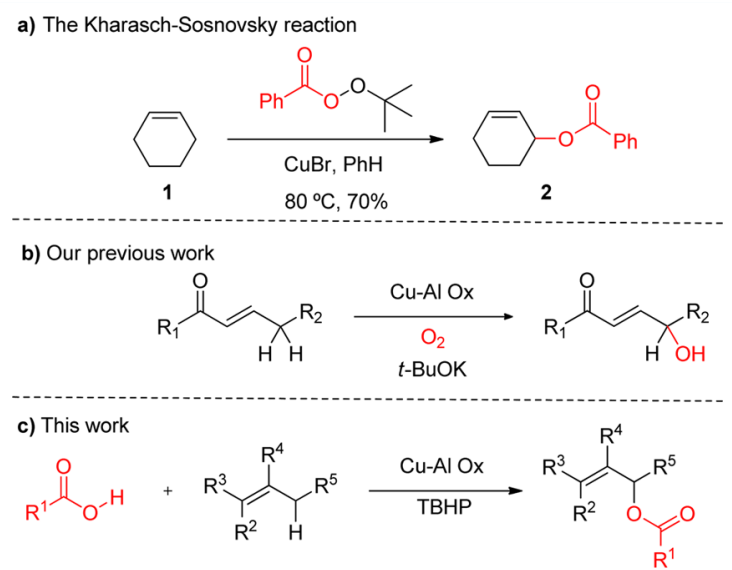

Figure 1. (a) Kharasch-Sosnovsky reaction; (b) use of $\mathrm{Cu}-\mathrm{Al} \mathrm{Ox}$ for the allylic oxidation of electron-deficient alkenes; (c) use of $\mathrm{Cu}-\mathrm{Al} \mathrm{Ox}$ for the allylic oxidation of electron-rich alkenes.

${ }^{\circ} \mathrm{C}, 24 \mathrm{~h}$ ) and then at open atmosphere (3 days), a fine powder is obtained. It consists of well-rounded grains in which copper and aluminum can be detected in all zones measured in a constant composition ( $\mathrm{Cu} 63.3 \%, \mathrm{Al} 9.1 \%$, EDS measures). ${ }^{9}$

The optimal performance of $\mathrm{Cu}-\mathrm{Al} \mathrm{Ox}$ in the oxidation of alkenones prompted us to investigate its use in the allylic oxidation of electron-rich alkenes. To this end, we first carried out an exploratory screening employing cyclohexene $\mathbf{1}$ and benzoic acid 3a. After some experimentation, good yields of cyclohexenyl benzoate $\mathbf{2}$ were obtained employing tert-butyl hydroperoxide (TBHP) as the oxidant.

It was also observed that the reaction was highly sensitive to the nature of the solvent, being quantitative when acetonitrile was employed (Table 1).

Received: January 20, 2014

Published: March 5, 2014 
Table 1. Oxidation of Cyclohexene with $\mathrm{TBHP}^{a}$

\begin{tabular}{|c|c|c|c|c|}
\hline entry & catalyst & solvent & temp $\left({ }^{\circ} \mathrm{C}\right)$ & yield $^{b}(\%)$ \\
\hline 1 & $\mathrm{Cu}-\mathrm{Al} \mathrm{Ox}$ & hexane & 69 & 20 \\
\hline 2 & $\mathrm{Cu}-\mathrm{Al} \mathrm{Ox}$ & $\mathrm{CH}_{2} \mathrm{Cl}_{2}$ & 40 & 82 \\
\hline 3 & $\mathrm{Cu}-\mathrm{Al} \mathrm{Ox}$ & pyridine & 115 & 37 \\
\hline 4 & $\mathrm{Cu}-\mathrm{Al} \mathrm{Ox}$ & $\mathrm{CH}_{3} \mathrm{CN}$ & 82 & 100 \\
\hline $5^{c}$ & $\mathrm{Cu}-\mathrm{Al} \mathrm{Ox}$ & $\mathrm{CH}_{3} \mathrm{CN}$ & 82 & 9 \\
\hline 6 & & $\mathrm{CH}_{3} \mathrm{CN}$ & 82 & 6 \\
\hline 7 & $\mathrm{CuCl}_{2}$ & $\mathrm{CH}_{3} \mathrm{CN}$ & 82 & 25 \\
\hline 8 & $\mathrm{AlCl}_{3} \cdot 6 \mathrm{H}_{2} \mathrm{O}$ & $\mathrm{CH}_{3} \mathrm{CN}$ & 82 & 4 \\
\hline $9^{d}$ & $\mathrm{CuCl}_{2}, \mathrm{AlCl}_{3} \cdot 6 \mathrm{H}_{2} \mathrm{O}$ & $\mathrm{CH}_{3} \mathrm{CN}$ & 82 & 51 \\
\hline
\end{tabular}

${ }^{a}$ All reaction were carried out using cyclohexene $1(4.0 \mathrm{mmol})$, benzoic acid 3a $(1.0 \mathrm{mmol})$, TBHP $(1.5 \mathrm{mmol})$, catalyst $(60 \mathrm{mg})$, solvent $(4 \mathrm{~mL}), 24 \mathrm{~h} .{ }^{b}$ Determined by GC. ${ }^{c}$ Without TBHP, oxygen from air as oxidant $\left(1 \mathrm{~atm}\right.$, vigorous stirring). ${ }^{d} \mathrm{CuCl}_{2}$ (33 mg), $\mathrm{AlCl}_{3}$. $6 \mathrm{H}_{2} \mathrm{O}(27 \mathrm{mg})$.

Several blank tests were run to evaluate the necessity of the use of $\mathrm{Cu}-\mathrm{Al} \mathrm{Ox}$ and the behavior of its parent precursors (entries $6-9$ ). The presence of $\mathrm{Cu}-\mathrm{Al} \mathrm{Ox}$ was essential since the yield of the corresponding ester dropped to only $6 \%$ in its absence (entry 6 ). TBHP was needed for the reaction to proceed, and the oxygen from the air did not work as the oxygen source (entry 5). It was also observed that the use of any $\mathrm{Cu}-\mathrm{Al} \mathrm{Ox}$ precursors led lower yields, demonstrating the superior catalytic activity of $\mathrm{Cu}-$ $\mathrm{Al} \mathrm{Ox}$.

We next turned to the substrate scope of simple cycloalkenes and carboxylic acids (Scheme 1). The yields ranged from moderate to excellent. Several aromatic carboxylic acids bearing different groups were employed. The presence of either an electron-withdrawing or an electron-releasing group in the aromatic ring of the carboxylic acids seemed not to affect the outcome of the reaction. In the case of cyclohexene, the results were excellent with all tested acids. There was more disparity when cyclopentene $\mathbf{4}$ and cyclooctene 5 were used. In the case of cyclopentene, the presence of a methoxyl group in the $p$-position of the aromatic ring led to a $85 \%$ yield of the ester 13 . The same acid led to a moderate $36 \%$ yield of $\mathbf{1 8}$ when cyclooctene was employed.

More complex alkenes were also evaluated (Scheme 2 ). In the case of the monoterpene $\beta$-pinene 20, the yields ranged from moderate to good. It is remarkable that no allylic transposition of the double bond was observed in contrast to other oxidation methods. In the case of the sesquiterpene valencene 21 , the yields were higher than those obtained in $\beta$-pinene, except in the case of acetate 33 (only 46\%). The nature of the group located in the aromatic ring did not affect the outcome of the reaction. The inertness shown by the exocyclic double bond of valencene under the reaction conditions was also remarkable.

Finally, the benzylic oxidation of indane $\mathbf{2 2}$ was studied. The reactions proceeded in a wide range of yields, from moderate in the case of acetate $39(26 \%)$ to good in the case of $p$ methoxybenzoate 37 ( $88 \%)$.

Most reports regarding the Kharasch-Sosnovsky reaction employ an excess of the olefin, with the oxidant being the limiting reagent. ${ }^{10}$ This fact restricts the use of this reaction in the case of valuable alkenes. In our case, except when the volatility is an issue, the reactions were carried out employing a 1:1 alkeneoxidant ratio.
Scheme 1. Oxidation of Simple Cycloalkenes with TBHP in the Presence of $\mathrm{Cu}-\mathrm{Al} \mathrm{Ox}^{a, b}$

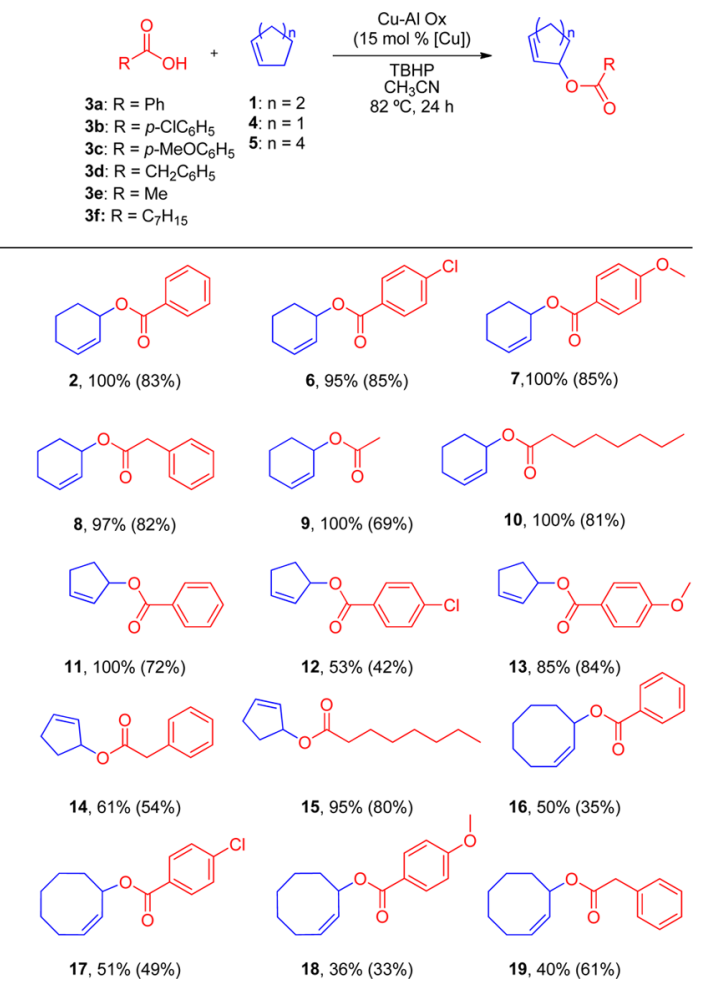

${ }^{a}$ All reactions were carried out using the cycloalkene $(4.0 \mathrm{mmol})$, carboxylic acids $3 \mathrm{a}-\mathrm{f}(1.0 \mathrm{mmol}), \mathrm{TBHP}(1.5 \mathrm{mmol}), \mathrm{Cu}-\mathrm{Al}$ Ox $(60$ $\mathrm{mg}$ ), refluxing $\mathrm{CH}_{3} \mathrm{CN}(4 \mathrm{~mL}), 24 \mathrm{~h} .{ }^{b} \mathrm{GC}$ yields (isolated yield).

According to the mechanisms proposed by Beckwith and Savitzas $^{11}$ and Mayoral et al. ${ }^{12}$ for the Kharasch-Sosnovsky reaction, a plausible mechanism for the present allylic oxidation is outlined in Scheme 3. In this mechanism, the solid $\mathrm{Cu}-\mathrm{Al} \mathrm{Ox}$ provides a surface in which coordination with the $\mathrm{Cu}$ or $\mathrm{Al}$ atoms may diminish the activation energy needed for the homolytic cleavage of the $\mathrm{O}-\mathrm{O}$ or the $\mathrm{C}-\mathrm{H}$ bonds of the TBHP or the cyclohexene, respectively. The presence of a second metallic atom in the close vicinity to the $\mathrm{Cu}$ atom would help to lock the reacting species. After formation of the cyclohexenyl radical, the carboxylic acid would be locked by the $\mathrm{Cu}$ or $\mathrm{Al}$ atoms. Finally, a pericyclic rearrangement would take place, providing the corresponding ester.

The use of amino acids as the carboxylic acid partner was also investigated. When we employed L-proline and cyclohexene as the olefin (Scheme 4), it was found that, contrary to the expected esterification process described above, only cyclohexenol $\mathbf{4 0}$ and cyclohexenone 41 were detected, although in low yield (12\% and $11 \%$, respectively).

Given that the reaction led to the formation of a free hydroxyl group or a ketone, a different mechanism should be considered. A possible explanation would involve the formation of a complex between the L-proline ligand and the copper atom of $\mathrm{Cu}-\mathrm{Al} \mathrm{Ox}$ as reported by the Ding ${ }^{13}$ and Stahl ${ }^{14}$ groups.

Since the mechanism of the latter transformation was unclear, its optimization was troublesome. This fact and the low yields obtained prompted us to employ a statistical approach, the design of experiments (DoE), to increase the yield. DoE is a statistical method that defines a domain for every variable involved in a reaction. Instead of changing one variable at a time 
Scheme 2. Oxidation of More Complex Alkenes with TBHP in the Presence of $\mathrm{Cu}-\mathrm{Al} \mathrm{Ox}^{a, b}$
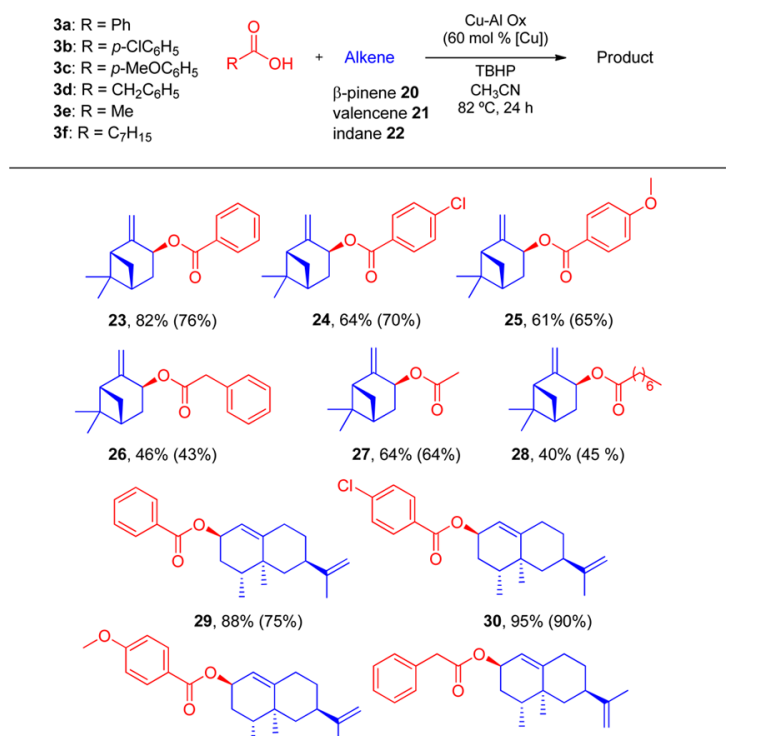

$31,100 \%(91 \%) \quad 32,98 \%(86 \%)$
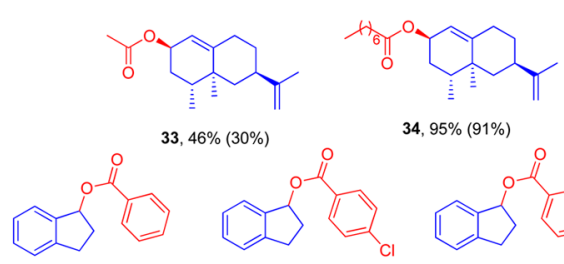

$34,95 \%(91 \%)$
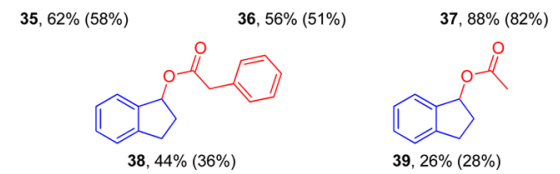

${ }^{a}$ All reactions were carried out using alkene $(1.0 \mathrm{mmol})$, carboxylic acids $3 \mathrm{a}-\mathbf{f}(1.0 \mathrm{mmol})$, TBHP (1.5 $\mathrm{mmol}$ for valencene $21,3.0 \mathrm{mmol}$ for $\beta$-pinene 20, and indane 22), $\mathrm{Cu}-\mathrm{Al} \mathrm{Ox}(60 \mathrm{mg})$, refluxing $\mathrm{CH}_{3} \mathrm{CN}(4 \mathrm{~mL}), 24$ h. ${ }^{b} \mathrm{GC}$ yields (isolated yield).

Scheme 3. Plausible Mechanism for the Allylic Oxidation of Alkenes with TBHP in the Presence of $\mathrm{Cu}-\mathrm{Al} \mathrm{Ox}$
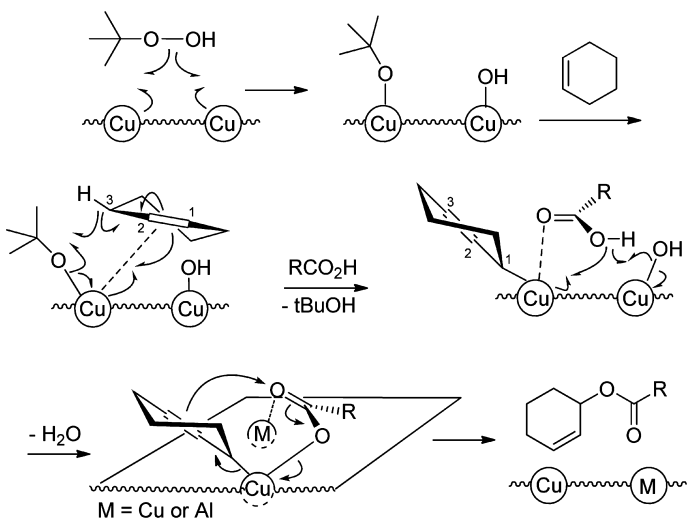

(an OVAT approach), this technique allows several variables to be changed at the same time. ${ }^{15}$ The experiments are run under the conditions determined by a chosen algorithm, and different yields are obtained. With these data in hand, a model that accounts for the dependence of the yield with regard to every variable studied can be calculated. It is then possible to predict
Scheme 4. Synthesis of Cyclohexenol and Cyclohexenone with TBHP in the Presence of $\mathrm{Cu}-\mathrm{Al} \mathrm{Ox}$ and L-Proline

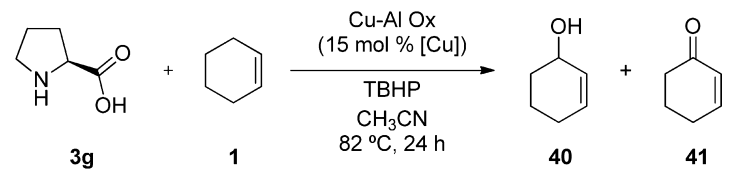

the yield of a given reaction under certain conditions or to optimize the conditions in order to obtain the highest possible yield.

Three variables were considered for the study: (i) the amount of $\mathrm{Cu}-\mathrm{Al} \mathrm{Ox}$, (ii) the equivalents of TBHP, and (iii) the temperature. The election of acetonitrile as the solvent set the temperature at $82^{\circ} \mathrm{C}$, enabling the cleavage of the $\mathrm{O}-\mathrm{O}$ bond of the TBHP. With only two variables, it was possible to perform a $3^{2}$ full-factorial design with two central points, which resulted in 11 experiments (see the Supporting Information for the experimental matrix).

This design increased the yield to $40 \%$ for cyclohexenol and $48 \%$ for cyclohexenone, which represents a $88 \%$ of overall oxidation yield, employing $15 \mathrm{mg} / \mathrm{mmol}$ of $\mathrm{Cu}-\mathrm{Al} \mathrm{Ox}$ and 6.0 equiv of TBHP at $82{ }^{\circ} \mathrm{C}$. The curved shape of the attained response surface (Figure 2) revealed that higher amounts of $\mathrm{Cu}-$ $\mathrm{Al} \mathrm{Ox}$ and TBHP would not result in significant higher yields.

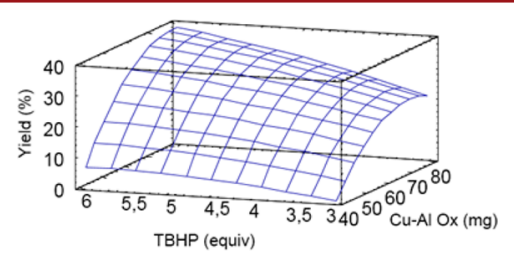

Figure 2. Calculated response surface for the synthesis of cyclohexenol 40.

The allylic oxidation of valencene employing $\mathrm{Cu}-\mathrm{Al} \mathrm{Ox}$, TBHP, and L-proline was studied next. We first carried out an experiment employing 1.5 equiv of TBHP and $60 \mathrm{mg} / \mathrm{mmol}$ of $\mathrm{Cu}-\mathrm{Al} \mathrm{Ox}$. In contrast to the results of cyclohexene, the reaction produced only nootkatone 42 (40\% yield), a valuable sesquiterpene commonly used in perfumery and cosmetics. ${ }^{16}$

Following the same methodology described above, a $3^{2}$ fullfactorial design, with 9 experiments and 2 extra central points, was conducted. The statistical analysis of the model thus obtained (see the Supporting Information) displayed that the main factor involved was the amount of $\mathrm{Cu}-\mathrm{Al} \mathrm{Ox}$ employed in the reaction. The amount of oxidant resulted irrelevant in the experimental domain. The response surface is displayed in Figure 3.

The best result corresponded to $60 \mathrm{mg} / \mathrm{mmol}$ substrate of $\mathrm{Cu}-\mathrm{Al} \mathrm{Ox}$ and 4.5 equiv of TBHP, which proceeded in $64 \%$ yield. The reaction yield was thus improved from 40 to $64 \%$.

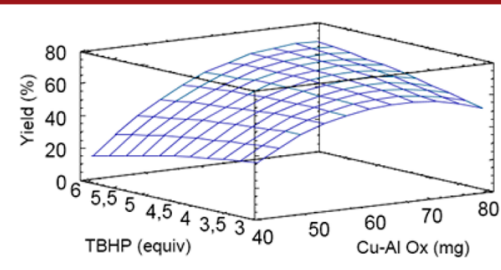

Figure 3. Response surface for the synthesis of nootkatone $\mathbf{4 2}$. 
Extension of the study to the allylic oxidation of of $\beta$-pinene and indane (Scheme 5) provided alcohol 43 and ketone 44, respectively, with excellent yields.

\section{Scheme 5. Oxidation of Alkenes in the Presence of $\mathrm{L}-$} Proline ${ }^{a, b}$

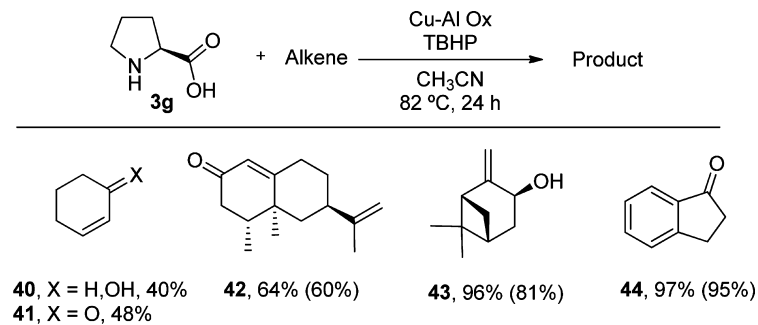

${ }^{a}$ All reactions were carried out using cyclohexene $1(4.0 \mathrm{mmol})$ and $\beta$ pinene 20, $(+)$-valencene 21 , and indane $22(1.0 \mathrm{mmol})$, L-proline $\mathbf{3 g}$ (1.0 mmol), TBHP $(6.0 \mathrm{mmol}$ for $\mathbf{1}$ and 20 and $4.5 \mathrm{mmol}$ for $\mathbf{2 1}$ and 22), $\mathrm{Cu}-\mathrm{Al} \mathrm{Ox}(60 \mathrm{mg} ; 15 \mathrm{~mol} \%[\mathrm{Cu}]$ for $\mathbf{1}, 60 \mathrm{~mol} \%[\mathrm{Cu}]$ for $\mathbf{2 0}$, 21, and 22), refluxing $\mathrm{CH}_{3} \mathrm{CN}(4 \mathrm{~mL}), 82{ }^{\circ} \mathrm{C}, 24 \mathrm{~h} .{ }^{b} \mathrm{GC}$ yields (isolated yield).

To verify the uniqueness of L-proline in this context, an amino acid and amine series were also tested, leading to poorer results compared to L-proline (see the Supporting Information).

In summary, we have demonstrated the capacity of $\mathrm{Cu}-\mathrm{Al} \mathrm{Ox}$ to catalyze the allylic oxidation of cyclic alkenes. The reactions are technically easy to perform and provide synthetically useful yields. In addition, DoE has revealed itself as a valuable tool for the optimization of these processes. The use of $\mathrm{Cu}-\mathrm{Al} \mathrm{Ox}$ discloses a promising route to the allylic oxidation of valuable alkenes. Its preparation is amenable to fine-tuning, and its chemical properties can thus be modulated. Its catalytic behavior in other reactions is currently under study.

\section{ASSOCIATED CONTENT}

\section{S Supporting Information}

Experimental procedures, DoE optimization details, compound characterization, and ${ }^{1} \mathrm{H} /{ }^{13} \mathrm{C}$ NMR reprints. This material is available free of charge via the Internet at http://pubs.acs.org.

\section{AUTHOR INFORMATION}

\section{Corresponding Author}

*E-mail: francisco.guerra@uca.es.

Notes

The authors declare no competing financial interest.

\section{ACKNOWLEDGMENTS}

This research was supported by Junta de Andalucía (FQM-169). The authors are thankful to the Servicios Centrales de Ciencia y Tecnología (SCCYT) of the University of Cádiz. A.L.G.-C. and R.M.-B. thank the Spanish Ministry of Education, Culture and Sport for a fellowship.

\section{REFERENCES}

(1) (a) White, M. C. Synlett 2012, 23, 2746-2748. (b) Wencel-Delord, J.; Dröge, T.; Liu, F.; Glorius, F. Chem. Soc. Rev. 2011, 40, 4740-4761. (c) Baran, P. S.; Newhouse, T. Angew. Chem., Int. Ed. 2011, 50, 33623374. (d) Bergman, R. G. Nature 2007, 446, 391-393. (e) Kalyani, D.; Deprez, N. R.; Desai, L. V.; Sanford, M. S. J. Am. Chem. Soc. 2005, 127, 7330-7331. (f) Kakiuchi, F.; Chatani, N. Adv. Synth. Catal. 2003, 345, 1077-1101. (g) Labinger, J. A.; Bercaw, J. E. Nature 2002, 417, 507-
514. (h) Dyker, G. Angew. Chem., Int. Ed. 1999, 38, 1698-1712. (i) Shilov, A. E.; Shul'pin, G. B. Chem. Rev. 1997, 97, 2879-2932.

(2) (a) Nakamura, A.; Nakada, M. Synthesis 2013, 45, 1421-1251. (b) Fraunhoffer, K. J.; Prabagaran, N.; Sirois, L. E.; White, M. C. J. Am. Chem. Soc. 2006, 128, 9032-9033. (c) Covell, D. J.; Vermeulen, N. A.; Labenz, N. A.; White, M. C. Angew. Chem., Int. Ed. 2006, 118, 83978400. (d) Ginotra, S. K.; Singh, V. K. Org. Biomol. Chem. 2006, 4, 43704374. (e) Fraunhoffer, K. J.; Bachovchin, D. A.; White, M. C. Org. Lett. 2005, 7, 223-226. (f) Zhou, J.; Tang, Y. Chem. Soc. Rev. 2005, 34, 664676. (g) Andrus, M. B.; Asgari, D. Tetrahedron 2000, 56, 5775-5780.

(3) Weidmann, V.; Maison, W. Synthesis 2013, 45, 2201-2221.

(4) (a) Delcamp, J. H.; White, M. C. J. Am. Chem. Soc. 2006, 128, 15076-15077. (b) Chen, M. S.; Prabagaran, N.; Labenz, N. A.; White, M. C. J. Am. Chem. Soc. 2005, 127, 6970-6971. (c) Chen, M. S.; White, M. C. J. Am. Chem. Soc. 2004, 126, 1346-1347.

(5) (a) McLaughlin, E. C.; Choi, H.; Wang, K.; Chiou, G.; Doyle, M. P. J. Org. Chem. 2009, 74, 730-738. (b) Choi, H.; Doyle, M. P. Org. Lett. 2007, 9, 5349-5352. (c) Catino, A. J.; Forslund, R. E.; Doyle, M. P. J. Am. Chem. Soc. 2004, 126, 13622-13623.

(6) (a) Kharasch, M. S.; Sosnovsky, G.; Yang, N. C. J. Am. Chem. Soc. 1959, 81, 5819-5824. (b) Kharasch, M. S.; Sosnovsky, G. J. Am. Chem. Soc. 1958, 80, 756.

(7) (a) Shi, E.; Shao, Y.; Chen, S.; Hu, H.; Liu, Z.; Zhang, J.; Wan, X. Org. Lett. 2012, 14, 3384-3387. (b) Akermark, B.; Magnus Larsson, E.; Oslob, J. D. J. Org. Chem. 1994, 59, 5729-5733.

(8) (a) Marín-Barrios, R.; Guerra, F. M.; García-Cabeza, A. L.; Moreno-Dorado, F. J.; Massanet, G. M. Tetrahedron 2012, 68, 11051108. (b) Andrus, M. B.; Lashley, J. C. Tetrahedron 2002, 58, 845-866. (c) Eames, J.; Watkinson, W. Angew. Chem., Int. Ed. 2001, 40, 35673571.

(9) García-Cabeza, A. L.; Marín-Barrios, R.; Azarken, R.; MorenoDorado, F. J.; Ortega, M. J.; Vidal, H.; Gatica, J. M.; Massanet, G. M.; Guerra, F. M. Eur. J. Org. Chem. 2013, 8307-8314.

(10) Le Bras, J.; Muzart, J. Tetrahedron: Asymetry 2003, 14, 19111915.

(11) Beckwith, A. L. J.; Zavitsas, A. A. J. Am. Chem. Soc. 1986, 108, 8230-8234.

(12) Mayoral, J. A.; Rodríguez-Rodríguez, S.; Salvatella, L. Chem.Eur. J. 2008, 14, 9274-9285.

(13) Zhang, G.; Han, X.; Luan, Y.; Wang, Y.; Wen, X.; Ding, C. Chem. Commun. 2013, 72, 7908-7910.

(14) Hoover, J. M.; Ryland, B. L.; Stahl, S. S. J. Am. Chem. Soc. 2013 $135,2357-2367$.

(15) For a general introduction to experimental design in chemistry, see: (a) Leardy, R. Anal. Quim. Acta 2009, 652, 161-172. (b) Carlson, R.; Carlson, J. E. Design and Optimization in Organic Synthesis, in Data Handling in Science and Technology, Elsevier, Amsterdam, 2005. (c) Bezerra, M. A.; Santelli, R. E.; Oliveira, E. P.; Villar, L. S.; Escaleira, L. A. Talanta 2008, 76, 965-977. (d) Araujo, P. W.; Brereton, R. G. TrAC, Trends Anal. Chem. 1996, 15, 26-31. (e) Araujo, P. W.; Brereton, R. G. TrAC, Trends Anal. Chem. 1996, 15, 63-70.

(16) (a) Neuenschwander, U.; Jensen, K. F. Ind. Eng. Chem. Res. 2014, 53, 601-608. (b) Wilson, C. W.; Shaw, P. E. J. Agric. Food. Chem. 1978, $26,1430-1432$. 